\section{Harvest, Handling, and Storage Recommendations for Improving Postharvest Quality of Blackberry Cultivars}

\author{
Brian Lawrence and Juan Carlos Melgar ${ }^{1}$
}

ADDITIONAL INDEX WORDS. postharvest disorder, red drupelet reversion, fresh weight, leakiness, fruit quality

SUMMARY. Maintaining shelf life and postharvest quality of blackberries ( Rubus subgenus $R u b u s$ ) from harvest to consumer is challenging for growers and packers due to several postharvest issues including fresh weight (FW) loss, red drupelet reversion, and fruit leakiness. The time of day blackberries are harvested, the time from harvest to cold storage, and the time in cold storage are factors that may alter the incidence and severity of these postharvest problems. In this experiment, blackberries from 10 cultivars were picked at two different times (7:00-7:30 AM and 10:00-10:30 AM), delivered to cold storage either immediately or following a 90-minute delay, and evaluated after 1 or 2 weeks in cold storage for FW loss, red drupelet reversion, and leakiness. The response of blackberry postharvest quality to time of harvest, delay to cold storage, and storage length was cultivar-specific. In summary, time of harvest, delay to cold storage or storage length did not affect cultivars Arapaho and Ouachita. Different harvest times did not affect FW or incidence of reddening, but increased leakiness in 'Chester' and 'Triple Crown'; thus, these two cultivars should be preferably harvested early in the morning. Our recommendation for 'Chester', 'Triple Crown', 'Osage', 'Prime-Ark ${ }^{\circledR}$ Traveler', and 'Von' is to store the fruit of these cultivars as soon as possible. Limiting cold storage to 1 week maintained postharvest quality for at least one attribute of most cultivars (all but Arapaho and Ouachita) compared with 2 weeks of storage.

$\mathrm{B}$ lackberry production is increasing worldwide to meet a growing demand from consumers, especially in the fresh market (Clark and Finn, 2014). Unfortunately, maintaining fruit-eating quality from harvest to table is a main challenge for the fresh-market blackberry industry (Salgado and Clark, 2016; Segantini et al., 2017), and consumer appeal is greatly influenced by the deterioration of fruit following harvest (Clark and Finn, 2008). To counteract these difficulties, extensive breeding efforts have resulted in enhanced flavors and quality attributes, including recent crispy genotypes with improved postharvest performance (Salgado and Clark, 2016). Harvest and handling practices have also improved, as they ultimately affect postharvest quality and shelf life (Clark and Finn, 2008). For instance, many

Department of Plant and Environmental Sciences,
Clemson University, 105 Collings Street, BRC 204, Clemson University,
Clemson, SC 29634

The authors thank the Musser Fruit Research Farm staff, Qi Zhou, Amanda Accampo, and Katlynn Murphy for their assistance in the field and the lab, and William Bridges for his assistance with statistics.

${ }^{1}$ Corresponding author. E-mail: jmelgar@clemson. edu.

https://doi.org/10.21273/HORTTECH04062-18 growers harvest early in the morning to minimize field heat and reduce the time before fruit is placed in cold storage.

Some of the most common and potentially devaluing defects in blackberry fruit are fresh weight (FW) loss, red drupelet reversion, and leakiness. Fresh weight loss occurs quickly since blackberries have high transpiration rates (Joo et al., 2011). These rates are often moderated by immediate cold storage but growers in many regions do not have in-field cold storage units, and both the time of harvest as well as amount of time from harvest to cold storage can affect final FW and postharvest quality. Red drupelet reversion, or reddening, is a common postharvest disorder by which drupelets revert from fully black to a bright red color (McCoy et al., 2016; Perkins-Veazie et al., 1996). Reversion is frequently observed following sudden temperature change after physical damage during harvest and shipping, or when exposed to room temperature after being in cold storage (Edgley, 2017; McCoy et al., 2016; Pérez-Pérez et al., 2018). Color reversion is theorized to be the result of internal cell structures rupturing and changing internal $\mathrm{pH}$, leading to the degradation or lack of formation of anthocyanin pigments (Edgley, 2017; Pérez-Pérez et al., 2018). Reddening has also been reported to increase if blackberries are harvested later in the day as temperature increases (McCoy et al., 2016). Finally, visible leakiness of fruit also limits marketability and can reduce fresh-market price. Both harvest and postharvest conditions are important as leakiness can be increased by high temperature and high ultraviolet index at harvest and by the storage duration (Liu, 2014; Perkins-Veazie et al., 1999).

Since many cultivars ripen simultaneously during the growing season and growers often pick large quantities of fruit before transferring to cold storage, understanding of the effect of management practices on fruit quality of specific cultivars is needed. Growers could prioritize the harvest of cultivars based on time of day, develop harvesting plans based upon the need for prompt cold storage, and improve marketing strategies depending on cold storage duration without affecting fruit quality.

The objectives of this study were to understand and identify best practices for harvesting and storing fruit from 10 of the most commonly planted thornless blackberry cultivars. We hypothesized that fruit from some cultivars would be more predisposed to reduced fruit quality than others if harvested later in the morning, if transfer to cooling was delayed, or if storage time was extended.

\section{Materials and methods}

STUDY SITE AND PLANT MATERIAL. The experiment was carried out at a 3-year-old blackberry plot at Clemson University's Musser Fruit Research Farm located in Seneca, SC

\begin{tabular}{llll}
\hline $\begin{array}{l}\text { Units } \\
\begin{array}{l}\text { To convert U.S. to SI, } \\
\text { multiply by }\end{array}\end{array}$ & U.S. unit & SI unit & $\begin{array}{l}\text { To convert SI to U.S., } \\
\text { multiply by }\end{array}$ \\
\hline 3.7854 & gal & $\mathrm{L}$ & 0.2642 \\
1.1209 & $\mathrm{lb} / \mathrm{acre}$ & $\mathrm{kg} \cdot \mathrm{ha}^{1}$ & 0.8922 \\
$\left({ }^{\circ} \mathrm{F}-32\right) \div 1.8$ & ${ }^{\circ} \mathrm{F}$ & ${ }^{\circ} \mathrm{C}$ & $\left({ }^{\circ} \mathrm{C} \times 1.8\right)+32$
\end{tabular}


(lat. $34^{\circ} 36^{\prime} 22^{\prime \prime} \mathrm{N}$, long. $\left.82^{\circ} 52^{\prime} 39^{\prime \prime} \mathrm{W}\right)$. The following 10 thornless blackberry cultivars were used (first and last harvest dates in parenthesis): Prime$\operatorname{Ark}^{\circledR}$ Traveler (22 May to 5 July), Arapaho (22 May to 5 July), Natchez (22 May to 13 July), Osage (25 May to 25 July), Ouachita (29 May to 25 July), Navaho (5 June to 9 Aug.), Apache (8 June to 9 Aug.), Von (19 June to 15 Aug.), Triple Crown (22 June to 9 Aug.), and Chester (5 July to 22 Aug.). There were five plants per cultivar replicated three times (three rows) in a randomized complete block design. Rows were covered with white plastic mulch and the entire plot was uniformly drip irrigated with $0.9 \mathrm{gal} /$ plant per hour for $3 \mathrm{~h}$ per week. Plants were fertigated weekly with liquid calcium nitrate from April to July and then monthly in August and September for total of $20 \mathrm{lb} /$ acre nitrogen per year.

Treatments. Blackberries were harvested between May and July 2017. Fruit were selected at random from each block of five plants across the three rows. To evaluate the effect of different harvest methods on postharvest quality, eight treatments resulting from a $2 \times 2 \times 2$ factorial were applied. The three main factors were 1) harvest time [fruit were harvested between 7:00 and 7:30 AM or between 10:00 and 10:30 AM (designated as 7:00 AM or 10:00 AM)]; 2) delayed cooling [fruit collected at both times was weighed (FWl) and a) placed immediately into cold storage $\left(4{ }^{\circ} \mathrm{C}\right)$ or b) placed to ambient outside temperature under the shade for 90 min before cold storage]; and 3) storage length (fruit were either stored in the cold chamber for 1 or 2 weeks).

At harvest, 18 fully ripe blackberries per treatment and cultivar were collected and placed into clear plastic, ventilated clamshell containers each containing a single absorbance pad (MP-30451P; Paper Pak Industries, La Verne, CA). Three containers (each container was a replicate) with six blackberries each were used to easily count red drupelets and see if there was fruit leakiness. Each cultivar was harvested three times during peak production (144 fruit per day, totaling 432 fruit), as shown in Table 1, except 'Prime-Ark ${ }^{\circledR}$ Traveler' which was harvested twice (288 fruit).

Fruit Quality evaluation. After cold storage, fruit were evaluated for percent FW loss, red drupelet reversion, and leakiness. Fresh weight loss percentage was calculated as: (FWl - FW2)/FWl, where FWl was the weight of the clamshell with fruit measured right after harvest, and FW2 was measured after clamshells were removed from cold storage and were at room temperature for $30 \mathrm{~min}$. A fruit containing more than five completely red drupelets was counted as a blackberry with color reversion. Color reversion (percent) was calculated as the average percentage of blackberries with color reversion per clamshell. The presence of leakiness $(+/-)$ was determined as visible staining on the absorbance pad inside the clamshell as a consequence of drupelet rupturing during storage. Leakiness percentage was calculated as the percentage of clamshells with leakiness.

Data AnAlysis. The main effects of harvest time, delay to cold storage, and storage time (along with their interactions) on FW loss, red drupelet reversion, and leakiness were analyzed by cultivar, using $\mathrm{JMP}^{\circledR}$ (version 12.2.0; SAS Institute, Cary, NC). A full factorial model with the three main factors (harvest time, delay to cold storage, and storage time) was analyzed using an analysis of variance (ANOVA). Student's least significant difference test was used for post hoc comparisons to identify statistical differences between factors. An additional ANOVA model including the variable of date of harvest was also examined to identify significant interactions between the three main factors and sample date. The effect of weather conditions [temperature and relative humidity $(\mathrm{RH})$ ] on postharvest attributes on different dates were studied using the data from the Weather Underground registered station [KSCSENEC14 (lat. $34^{\circ} 36^{\prime} 11^{\prime \prime} \mathrm{N}$, long. $\left.\left.82^{\circ} 52^{\prime} 43^{\prime \prime} \mathrm{W}\right)\right]$ at the Musser Fruit Research Farm.

Table 1. Harvest dates of each blackberry cultivar, and temperature and relative humidity (RH) for each date at the time of harvest.

31 May 7 June 14 June 21 June 23 June 28 June 7 July 12 July 17 July 19 July 24 July 26 July

\begin{tabular}{|c|c|c|c|c|c|c|c|c|c|c|c|c|}
\hline \multicolumn{13}{|l|}{ Cultivar $^{z}$} \\
\hline Natchez & $\mathrm{X}$ & & $\mathrm{X}$ & $\mathrm{X}$ & & & & & & & & \\
\hline Arapaho & & $\mathrm{X}$ & & $\mathrm{X}$ & $\mathrm{X}$ & & & & & & & \\
\hline $\begin{array}{c}\text { Prime-Ark }^{\circledR} \\
\text { Traveler }\end{array}$ & & $\mathrm{X}$ & $\mathrm{X}$ & & & & & & & & & \\
\hline Osage & $\mathrm{X}$ & $\mathrm{X}$ & $\mathrm{X}$ & & & & & & & & & \\
\hline Ouachita & & & & $\mathrm{X}$ & $\mathrm{X}$ & $\mathrm{X}$ & & & & & & \\
\hline Navaho & & & & & $\mathrm{X}$ & $\mathrm{X}$ & $\mathrm{X}$ & & & & & \\
\hline Apache & & & & & & & $\mathrm{X}$ & $\mathrm{X}$ & $\mathrm{X}$ & & & \\
\hline Triple Crown & & & & & & & & $\mathrm{X}$ & $\mathrm{X}$ & $\mathrm{X}$ & & \\
\hline Von & & & & & & & $\mathrm{X}$ & $\mathrm{X}$ & $\mathrm{X}$ & & & \\
\hline Chester & & & & & & & & & & $\mathrm{X}$ & $\mathrm{X}$ & $\mathrm{X}$ \\
\hline \multicolumn{13}{|c|}{ Temperature $\left({ }^{\circ} \mathrm{C}\right)^{\mathrm{y}}$} \\
\hline 7:00 AM & 20 & 18 & 21 & 21 & 22 & 17 & 23 & 23 & 21 & 21 & 22 & 21 \\
\hline 10:00 AM & 22 & 20 & 26 & 24 & 26 & 26 & 28 & 27 & 24 & 27 & 26 & 27 \\
\hline \multicolumn{13}{|l|}{ RH (\%) } \\
\hline 7:00 АM & 93 & 80 & 96 & 96 & 96 & 83 & 90 & 92 & 96 & 94 & 95 & 93 \\
\hline 10:00 АM & 84 & 72 & 86 & 89 & 87 & 60 & 78 & 79 & 84 & 82 & 83 & 81 \\
\hline
\end{tabular}

${ }^{\mathrm{z}}$ All cultivars were picked across three different sample dates with an exception to Prime-Ark ${ }^{\circledR}$ Traveler, picked twice.

${ }^{\mathrm{y}}\left(1.8 \times{ }^{\circ} \mathrm{C}\right)+32={ }^{\circ} \mathrm{F}$. 


\section{Results}

The responses of blackberries to harvest time, delay to cold storage, and weeks of cold storage were cultivarspecific (Table 2 ). Fruit decay as a consequence of mold was almost nonexistent, and the few cases observed across the season were random and not as a consequence of any treatment (data not shown).

Fresh weight Loss. Total FW loss of blackberries was not statistically different $(P>0.05)$ between the two harvest times for any cultivar (Table 2) although Von had a significant interaction $(P \leq 0.05)$ between the harvest time and weeks in cold storage (data not shown). Fruit of 'Chester', 'Osage', 'Prime-Ark ${ }^{\circledR}$ Traveler', 'Triple Crown', and 'Von' had a significant increase $(P \leq 0.05)$ of FW loss when they were delayed to cold storage, and 'Apache', 'Chester', 'Navaho', 'Osage',
'Prime-Ark ${ }^{\circledR}$ Traveler', and 'Triple Crown' had increased FW loss $(P \leq$ $0.05)$ if kept in cold storage for 2 weeks (Table 2).

RED DRUPELET REVERSION. The incidence of red drupelet reversion was not statistically different $(P>0.05)$ between the two harvest times for any cultivar (Table 2). Color reversion tended to be numerically higher when cold storage was delayed for most cultivars but only Von showed statistically higher values with a 90 -min delay $(P \leq 0.05)$. On the contrary, 'Apache' $(P \leq 0.001)$ had much higher color reversion with no delay. The greatest influence on color reversion was the duration of cold storage. The cultivars Apache, Chester, Natchez, Osage, Prime-Ark ${ }^{\circledR}$ Traveler, and Von had significantly higher color reversion $(P \leq 0.05)$ following 2 weeks of storage in comparison with 1 week.
LEAKINESS. Harvesting at 10:00 AM increased leakiness for 'Chester' $(P \leq 0.01)$ and 'Triple Crown' $(P \leq$ $0.05)$ with respect to early morning harvesting at 7:00 AM (Table 2). 'Natchez' showed more leakiness with a 90-min delay to cold storage $(P \leq$ 0.05 ), while 2 weeks of cold storage increased the amount of leakiness observed in 'Apache' $(P \leq 0.05)$ and 'Chester' $(P \leq 0.01)$.

INTERACTION WITH SAMPLE DATE. There were significant differences between sample dates regarding reddening $(\mathrm{F}=15.39, P \leq 0.001)$, leakiness $(\mathrm{F}=8.37, P \leq 0.001)$, and $\mathrm{FW}$ loss $(\mathrm{F}=78.44, P \leq 0.001)$ across all cultivars, where each independent variable was highly influenced by the sample date $(P \leq 0.001)$. However, the influence of the sample date in regard to FW loss, color reversion, and leakiness varied among cultivars (Table 3 ).

Table 2. Mean percent of fresh weight (FW) loss per clamshell, average percentage of blackberries with five or more red drupelets per clamshell, and percentage of clamshells with leakiness as a result of the management practices of harvest time, delay to cold storage, and duration of cold storage of 10 blackberry cultivars during the summer of 2017. Percentages are derived from three sample dates per cultivar except Prime-Ark ${ }^{\circledR}$ Traveler, harvested twice.

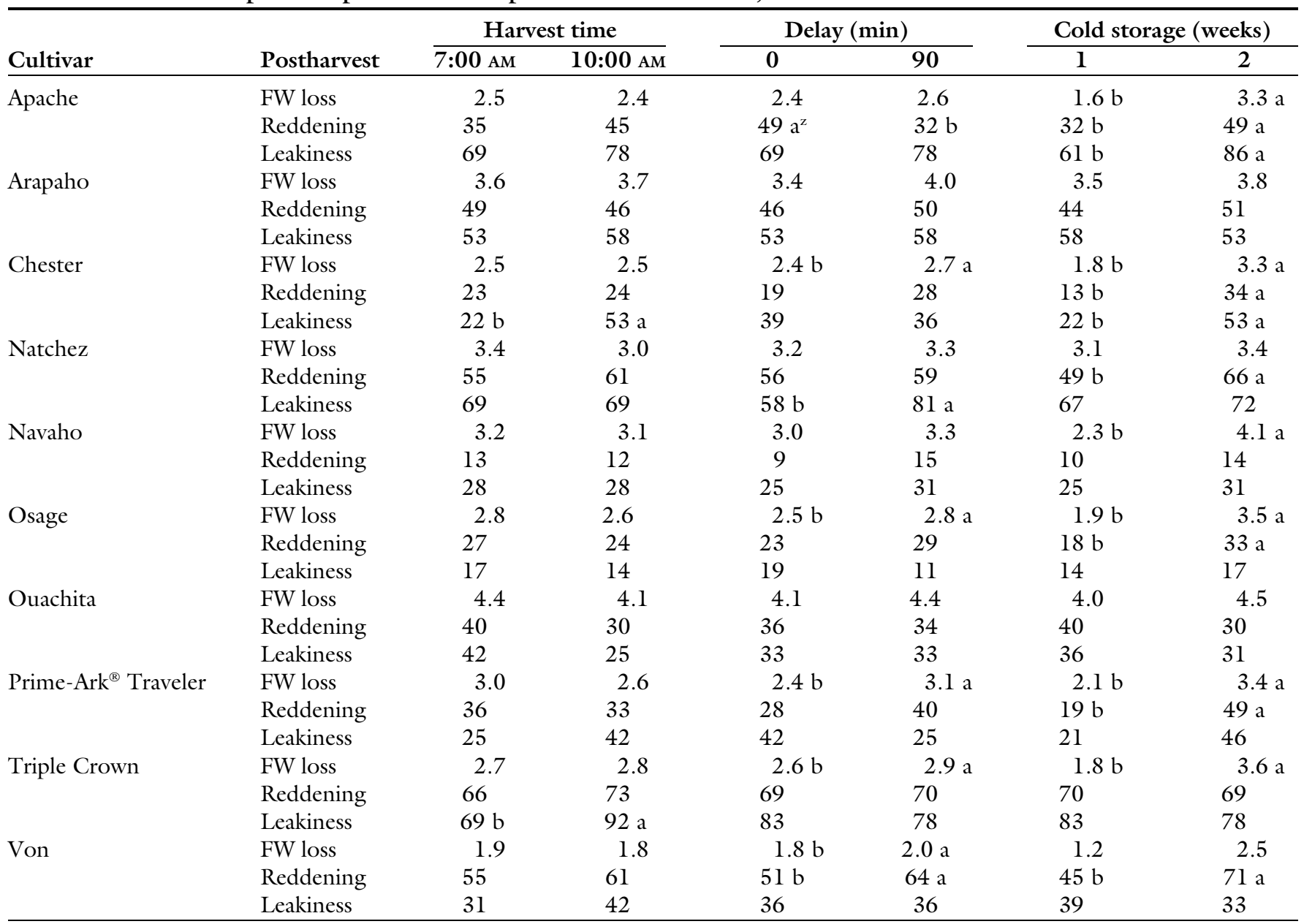

${ }^{\mathrm{z}}$ Mean separation letters following numbers in the same row under a specific management practice represent significant differences at $\alpha=0.05$ using Student's least significant difference test. 
Table 3. Significant interactions between the sample date and the main effects of harvest time, delay to cold storage, and weeks in storage by quality attributes of 10 blackberry cultivars.

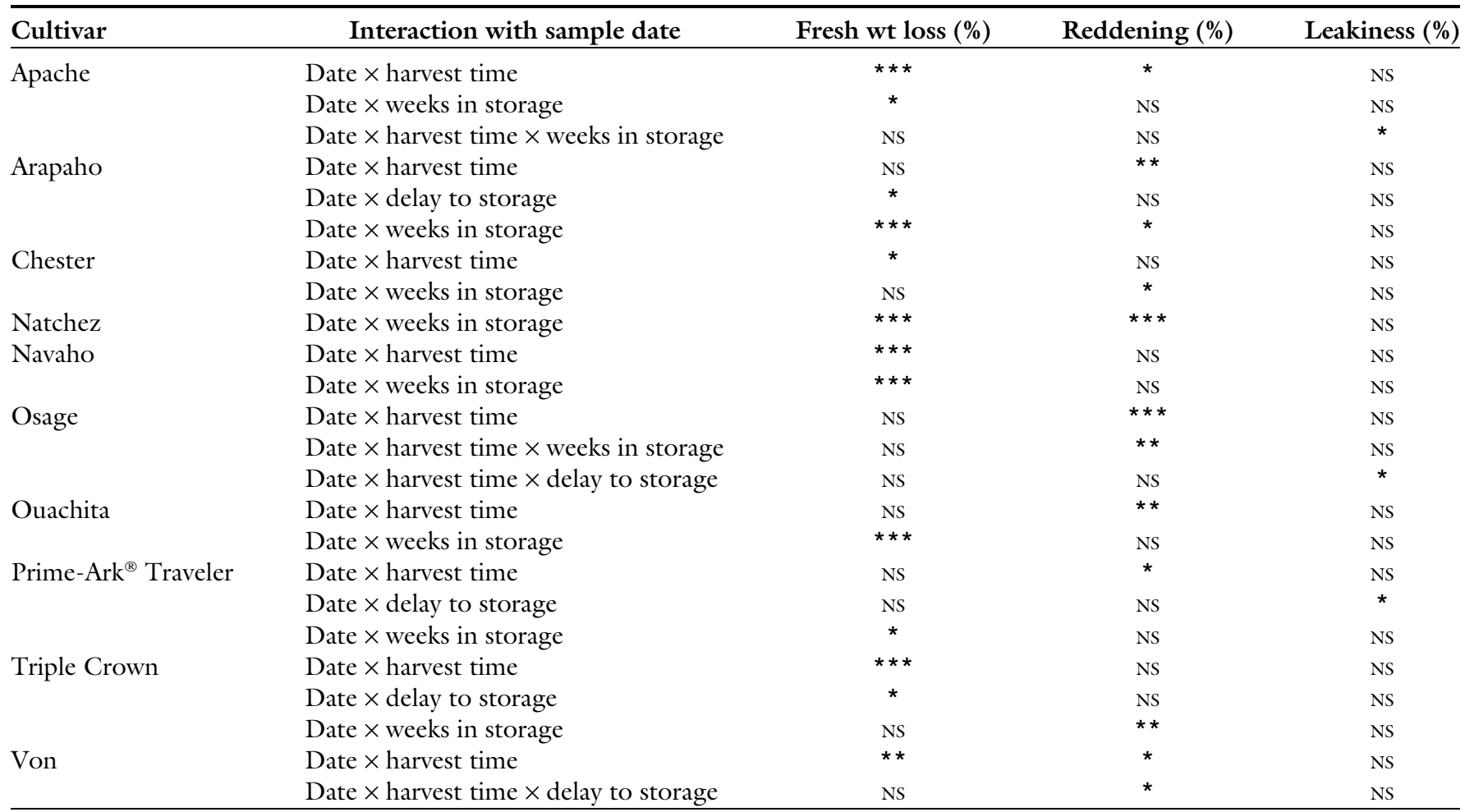

Ns, ${ }^{*},{ }^{* *},{ }^{* *}$ Nonsignificant or significant at $P \leq 0.05,0.01$, or 0.001 , respectively.

Overall, the interactions of main effects with the sample date highly influenced both FW loss and reddening, whereas leakiness within individual cultivars was less often affected.

\section{Discussion}

Fresh weight loss was unaffected by harvest time for all cultivars studied, but was significantly influenced by the interaction of sample date and harvest time in several cultivars. This interaction was observed among those cultivars harvested at higher average temperatures later in the season ('Navaho', 'Apache', 'Triple Crown', 'Von', and 'Chester'), which suggests that warmer temperatures in the field at harvest increase FW loss during postharvest.

Although different harvest times did not show any significant differences in color reversion across cultivars studied, most cultivars showed interaction between the sample date and harvest time, with harvest time increasing, decreasing or not affecting reddening depending on the sample date. Incidence of color reversion has been suggested to be associated with different harvest times [significantly lower on fruit harvested at 7:00 $\mathrm{AM}$ in comparison with 10:00 AM and two subsequent harvesting times (McCoy et al., 2016)], and rapid temperature changes (Salgado and Clark, 2016). The interaction between sample date and harvest time observed in our results suggests that while the main effect of harvest time was not significant as proposed by McCoy et al., (2016), this could be due to different environmental conditions in the two studies. Environmental conditions such as temperature, $\mathrm{RH}$, and plant water status at harvest, as well as other orchard management practices such as nitrogen fertilization, can influence red drupelet development (Edgley, 2017); different environmental conditions among sample dates could, therefore, have influenced color reversion more than harvest time.

An analysis of red drupelet incidence across cultivars failed to show any significant correlation with $\mathrm{RH}$ $\left(\mathrm{y}=-0.006 \mathrm{x}+2.910, R^{2}=0.002\right)$, nor with temperature $(\mathrm{y}=0.035 \mathrm{x}-0.198$, $R^{2}=0.010$ ) across all sample dates at the two harvest times. Additional analysis of cultivars showing the highest level of reversion also provided weak correlation with temperature or humidity. Since cultivars were picked across different days, cultivars which showed no statistical difference in reddening between sample dates may have been picked under similar $\mathrm{RH}$ and temperature. Likewise, a cultivar which was harvested under particularly dry or warm conditions and compared with the other two sample dates could show an increase or decrease of color reversion. Changes in incidence of red drupelet reversion for each specific cultivar and sample date showed that reddening (averaged over the three sample dates) at 10:00 AM was either the same or higher than at 7:00 AM. However, a detailed look at reddening on single dates revealed that there were two days when $\mathrm{RH}$ was lower than 90\% and/or temperature was lower than $20^{\circ} \mathrm{C}$ at 7:00 AM; on these specific dates, fruit harvested at 7:00 AM showed higher incidence of red drupelet reversion than fruit at 10:00 AM. Thus, specific environmental conditions may play a key role in increasing red drupelet reversion.

Understanding the influence of $\mathrm{RH}$ and temperature at harvest time on red drupelet incidence was not an objective of this study and blackberries in our trial were not picked 
purposely considering specific $\mathrm{RH}$ or temperatures. Indeed, there were only two dates where these conditions $\left(\mathrm{RH}<90 \%\right.$, temperature $<20^{\circ} \mathrm{C}$ ) occurred at 7:00 AM and, even though this trend seemed consistent for all five cultivars harvested these days, more data are needed to draw conclusions. Identifying these temperatures and $\mathrm{RH}$ ranges which may affect blackberry postharvest quality is worth further exploration.

Only two cultivars, Triple Crown and Chester, had a significant increase of leakiness at a later harvest time. Both of these cultivars matured at the end of the blackberry season during the warmest days of the study and higher temperatures could have had negative effects on fruit firmness (Salgado and Clark, 2016), contributing to higher frequency of leakiness. Other authors have not found decreased fruit firmness at warmer temperatures (McCoy et al., 2016) but we cannot rule out the influence of using different cultivars.

Delay to cold storage significantly increased FW loss in 'Chester', 'Osage', 'Prime-Ark ${ }^{\circledR}$ Traveler', 'Triple Crown', and 'Von'. Of these five cultivars, Chester, Triple Crown, and Von were delayed twice on days with outside temperatures above $28.5^{\circ} \mathrm{C}$ while Osage and Prime-Ark ${ }^{\circledR}$ Traveler were delayed once above $28^{\circ} \mathrm{C}$. These warmer conditions during the time of delay to cold storage could have increased FW loss in these cultivars. However, other cultivars harvested during the same days (and consequently with the same temperatures during delay to cold storage) did not show reduction in FW. This was the case for 'Apache', which was harvested together with 'Von'. Similarly, while incidence of reddening significantly decreased in frequency on 'Apache' fruit following a delay to cold storage, it significantly increased on 'Von'. Thus, the susceptibility to FW loss and the tendency of color reversion as a result of delay to cold storage is perhaps best rationalized by genetic differences between the two cultivars (McCoy et al., 2016; Salgado and Clark, 2016). Finally, the delay to cold storage had little effect on total leakiness except for 'Natchez', which showed a significant increase following the 90 min delay.

Regarding the duration of cold storage, blackberries stored for 2 weeks consistently had higher FW loss than those stored I week, yet several cultivars, including Arapaho, Natchez, Ouachita, and Von, showed insignificant FW loss under cold storage. Although FW loss is strongly dependent upon the genotype of cultivar (Segantini et al., 2017), our data suggest that different environmental conditions in combination with strategies of harvest lead to differences in total FW loss, with strong interaction between the sample date and harvest time for 'Apache', 'Navaho', and 'Triple Crown', and between sample date and the week of storage for 'Arapaho', 'Natchez', 'Navaho', and 'Ouachita'. Most cultivars showed a significant increase of reddening following 2 weeks of cold storage, with the exception of Arapaho, Navaho, Ouachita, and Triple Crown. However, 'Arapaho', 'Navaho', and 'Ouachita' had significant interaction with sample date and weeks of cold storage, revealing an environmental influence on reddening. The late-season cultivars Apache and Chester were harvested under high temperatures, and it is well known that increased temperature can have negative impacts on blackberry firmness and postharvest quality (Salgado and Clark, 2016). These cultivars could have been less firm than other cultivars picked under cooler temperatures and this could explain the greater incidence of leakiness following 2 weeks of storage.

Overall, the different harvest and postharvest treatments had less effect on leakiness compared with reddening development and FW loss. Certainly the genotype determines fruit firmness (Clark and Finn, 2008; Salgado and Clark, 2016), and environmental conditions such as high temperatures or low RH (Salgado and Clark, 2016) could lead to softer fruit, but our study showed only some interaction of leakiness between sample dates, suggesting leakiness remains highly variable.

Postharvest quality of blackberries will continue to be improved through breeding programs (Salgado and Clark, 2016), but additional focus on how management strategies influence postharvest quality can provide growers with the best options for current cultivars and plantings. Our study shows that some cultivars may become more susceptible to postharvest disorders that affect shelf life after certain harvesting and handling practices. For example, different harvest times did not affect $\mathrm{FW}$ or incidence of reddening but increased leakiness in 'Chester' and 'Triple Crown'; thus, these two cultivars should be preferably harvested early in the morning. Since the delay in taking the fruit to cold storage increased FW loss for 'Chester', 'Triple Crown', 'Osage', 'Prime-Ark ${ }^{\circledR}$ Traveler', and 'Von', our recommendation is to store the fruit of these cultivars as soon as possible. Some of these same cultivars (Chester, Triple Crown, Osage, and Prime-Ark ${ }^{\circledR}$ Traveler) also showed increased FW loss if fruit is stored for 2 weeks. Limiting cold storage to 1 week maintained postharvest quality of all cultivars but Arapaho and Ouachita for at least one attribute, compared with 2 weeks of cold storage. Indeed, only 'Arapaho' and 'Ouachita' showed no significant differences in FW loss, red drupelet reversion or leakiness as a consequence of our treatments, although both had significant main effect interactions with the sample date. Further studies are needed to understand individual cultivar responses between years of study, especially under different environmental conditions.

In summary, postharvest quality traits related to shelf life and consumer acceptance including FW loss, red drupelet reversion, and leakiness are highly dependent on harvest and handling practices. Our study showed that responses to different harvest times, delay before cold storage, or more weeks in cold storage were highly cultivar specific but each of these factors also had interactions with the sample date, which indicates the importance of environmental conditions at harvest time. Thus, further studies should focus on how variables such as temperature and RH affect postharvest quality on individual cultivars, especially for climates where there is high weather variability between days and even different hours of the day during the harvesting season.

\section{Literature cited}

Clark, J.R. and C.E. Finn. 2014. Blackberry cultivation in the world. Rev. Bras. Frutic. 36(1):46-57.

Clark, J.R. and C.E. Finn. 2008. New trends in blackberry breeding. Acta Hort. 777:41-48. 
Edgley, M. 2017. Managing red drupelet disorder. Perennial Hort. Fact Sheet. Tasmanian Inst. Agr., Hobart, Tasmania.

Joo, M., N. Lewandowski, R. Auras, J. Harte, and E. Almenar. 2011. Comparative shelf life study of blackberry fruit in bio-based and petroleum-based containers under retail storage conditions. Food Chem. 126:1734-1740.

Liu, M. 2014. Effect of organic production system and harvest date on the quality of blackberry fruit for fresh and processed markets. M.Sc. Thesis, Oregon State Univ., Corvallis.

McCoy, J.E., J.R. Clark, A.A. Salgado, and A. Jecmen. 2016. Evaluation of harvest time/temperature and storage temperature on postharvest incidence or red drupelet reversion development and firmness of blackberry ( $R u b u s$ L. subgenus Rubus Watson). Discovery (Read.) 17:59-65.

Pérez-Pérez, G.A., M.J. Fabela-Gallegos, M.E. Vázquez-Barrios, D.M. RiveraPastrana, L. Palma-Tirado, E. MercadoSilva, and V. Escalona. 2018. Effect of the transport vibration on the generation of the color reversion in blackberry fruit. Acta Hort. 1194:1329-1336.

Perkins-Veazie, P., J.K. Collins, and J.R. Clark. 1996. Cultivar and maturity affect postharvest quality of fruit from erect blackberries. HortScience 31:258-261.
Perkins-Veazie, P., J.K. Collins, and J.R. Clark. 1999. Cultivar and storage temperature effects on the shelflife of blackberry fruit. Fruit Var. J. 53:201-208.

Salgado, A. and J.R. Clark. 2016. "Crispy" blackberry genotypes: A breeding innovation of the university of Arkansas blackberry breeding program. HortScience $51: 468-471$.

Segantini, D.M., R. Threlfall, J.R. Clark, C.R. Brownmiller, L.R. Howard, and L.J.R. Lawless. 2017. Changes in fresh-market and sensory attributes of blackberry genotypes after postharvest storage. J. Berry Res. 7:129-145. 